\title{
PREFERENTIAL GROWTH OF SECONDARY RECRYSTALLIZED GOSS GRAINS DURING SECONDARY RECRYSTALLIZATION ANNEALING IN GRAIN ORIENTED SILICON STEEL SHEET
}

\author{
YUKIO INOKUTI* \\ *Research Laboratories, Kawasaki Steel Corp., Kawasaki-cho, Chuo-ku, \\ Chiba 260 Japan
}

(Received 5 January 1996)

Computer color mapping of the primary and secondary recrystallized Goss grains which formed during secondary recrystallization annealing was performed with an image analyzer, using crystallographic orientation data measured by a Kossel examination.

The preferential growth of secondary recrystallized Goss grains took place in a defined zone at the $1 / 10$ depth beneath the surface of the as-decarburized and primary recrystallized steel sheet.

With short-time secondary recrystallization annealing, a secondary recrystallized Goss grain with an $80 \times 50 \mu \mathrm{m}$ elliptical form grew preferentially in its defined zone.

With further secondary recrystallization annealing, four secondary recrystallized Goss grains coalesced to sizes of $100-350 \mu \mathrm{m}$, and exhibited a zigag morphology due to a difference in the degree of consumption of primary recrystallized grains by the secondary recrystallized Goss grains. Primary recrystallized grains with $\{100\}<001>,\{100\}<0 \mathrm{k} 1>$, and $\{100\}<011>$ orientations were resistant to comsumption by secondary recrystallized Goss grains, but those with $\{110\}<001>$ and $\{111\}<112>$ orientations were easily consumed by secondary recrystallized Goss grains.

With long-time secondary recrystallized annealing, the full thickness of the silicon steel sheet was occupied by giant secondary recrystallized Goss grains, which ultimately extended to lengths of several millimeters. The orientation of the secondary recrystallized Goss grains is highly aligned to the [001] axis rather than the (110) crystallographic plane.

It is considered that the nuclei for preferentially developing secondary recrystallized grains are inherited by the structure memory from highly oriented (110)[001] areas at the $1 / 10$ depth beneath the surface of hot-rolled silicon steel sheet.

KEY WORDS: Grain oriented silicon steel sheet; secondary recrystallized grain; primary recrystallized grain; Goss nuclei; defined zone; structure memory; Kossel examination; image analyzer; computer color map.

\section{INTRODUCTION}

The control of secondary recrystallized grains to obtain the Goss texture, (110)[001], is of vital importance in manufacturing silicon steel strip for transformer cores. The improvement of magnetic properties in grain oriented silicon steel sheet has been closely related to the history of improvements in the secondary recrystallized texture. The key point is to clarify the mechanism of preferential growth of the secondary recrystallized Goss grains, because research to date has not explained why Goss texture grains with 
the (110)[001] orientation grow preferentially during secondary recrystallization treatment.

Goss secondary nuclei for preferentially developing secondary recrystallized grains are generated from the highly oriented (110)[001] areas near the surface of hot-rolled silicon steel sheet. These highly oriented (110)[001] areas are inherited from the structure memory (Inokuti, 1988, Gol' dshten et al., 1978 and Inokuti et al., 1982 and 1985) in the vicinity of the surface of the silicon steel sheet after the as-decarburized and primary recrystallized annealing treatment that follows the first cold rolling, intermediate annealing, and second cold rolling operations.

With subsequent secondary recrystallization annealing, the colonies of primary large recrystallized (110)[001] grains in the vicinity of the steel surface show preferential growth. (Inokuti, 1988 and Inokuti et al., 1985) It is important to clarify the mechanism of nucleation and preferential growth of the secondary recrystallized Goss grains. To understand this mechanism better, it is necessary to study in detail hot-rolled silicon steel sheets, in which there are potential nuclei for Goss grains, and the many subsequent processes up to final secondary recrystallized grains and clarify the mechanism of inheritance from these nuclei, it is necessary to measure in detail the orientation and strain of small areas $(5-20 \mu \mathrm{m})$ or small grains during the processes from hot rolling to secondary recrystallization treatment. The selected area channeling pattern (SACP) method (Harase et al., 1986) and Kossel apparatus (Inokuti et al., 1980) have been developed for this purpose. Moreover, computer color mapping (Inokuti et al., 1986, 1990 and 1991) has been performed with an image analyzer, using the orientation data measured by a Kossel examination, to clarify the mechanism by which secondary recrystallized grains with the Goss orientation develop preferentially.

This paper discusses the preferential growth of secondary recrystallized Goss grains from Goss nuclei in the initial stage of secondary recrystallization up to the development of final giant secondary recrystallized Goss grains. The findings were obtained by computer color mapping with an image analyzer, using crystallographic orientation data measured by a Kossel examination. In particular, this work focuses on the preferential growth of secondary recrystallized grains, which grow preferentailly from defined zones in the vicinity of the silicon steel surface after as-decarburized and primary recrystallized annealing treatment prior to secondary recrystallization.

\section{EXPERIMENTAL PROCEDURE}

The materials used in the present investigation were as-decarburized and primary recrystallized silicon steel sheets $0.3 \mathrm{~mm}$ in thickness having the principal composition (mass \%) of Si: 3.0, Mn: 0.06, Se: 0.023, and Sb: 0.025. This silicon steel sheet was manufactured by a two-stage cold rolling process with intermediate annealing. Secondary recrystallization annealing was performed in flowing argon gas for $3 \mathrm{~h}, 7 \mathrm{~h}, 27 \mathrm{~h}$, and $50 \mathrm{~h}$ at $850^{\circ} \mathrm{C}$.

In the initial stage of the secondary recrytallization annealing, secondary recrystallized Goss grains grow preferentially from the vicinity of the steel surface, so samples were taken from an area at the $1 / 10$ depth beneath the steel surface after $3 \mathrm{~h}$ and $7 \mathrm{~h}$ annealing at $850^{\circ} \mathrm{C}$, and those of materials given $27 \mathrm{~h}$ and $50 \mathrm{~h}$ annealing at $850^{\circ} \mathrm{C}$ were taken from the center of the steel sheet. To obtain samples of materials annealed for $3 \mathrm{~h}$ and $7 \mathrm{~h}$ at $850^{\circ} \mathrm{C}$ for the transmission Kossel (TK) examination, thin samples were prepared by cutting the silicon steel sheets into $30 \times 40 \mathrm{~mm}^{2}$ pieces, and which were 
mechanically ground on one side to a thickness of about $150 \mu \mathrm{m}$. The unground steel surface was then protected with vinyl tape, and the sample was thinned in a $3 \% \mathrm{HF}$ $+\mathrm{H}_{2} \mathrm{O}_{2}$ solution to a thickness of about $60 \mu \mathrm{m}$. The vinyl tape was removed from the steel surface and the sample was thinned from both sides to about $10 \mu \mathrm{m}$ in a $3 \% \mathrm{HF}+\mathrm{H}_{2} \mathrm{O}_{2}$ solution, and finally etched with $3 \%$ nital. For samples of materials annealed for $27 \mathrm{~h}$ and $50 \mathrm{~h}$ at $850^{\circ} \mathrm{C}$, thin samples were prepared by cutting the silicon steel sheets into $30 \times 40 \mathrm{~mm}^{2}$ pieces, which were mechanically ground on both sides to a thickness of $120 \mu \mathrm{m}$, thinned to about $10 \mu \mathrm{m}$ from both sides of the sample, and finally etched with $3 \%$ nital.

Representative areas of the microstructure of the primary and secondary recrystallized grains which formed during secondary recrystallization were selected with an optical microscope, and the orientations of the primary and secondary recrystallized grains were determined in detail with the TK apparatus (Inokuti, 1980). Details of the method of TK examination and analysis have been reported previously (Inokuti, 1980 and Inokuti et al., 1983 and 1987).

Computer color mapping of the crystallographic orientation of the secondary and primary recrystallized grains was done with two image analyzers, the new one (Miyajima et al., 1990) being used to produce the maps of (B), (D) and (E) in Figure 1, and older Luzex 5000 (Furukimi et al., 1984) being used for map (C) in Figure 1.

Color maps of the secondary and primary recrystallized grains were displayed by an image analyzer, in terms of the orientation in the normal and rolling directions (ND and $\mathrm{RD}$ ) and directly photographed in color from the display.

Data $(\gamma, \phi)$ measured by a chart from the Kossel diffraction patterns were converted by computational processing into the parameters (Maeda et al., 1986) necessary for stereographic presentation on the unit triangle, showing ND for the crystallographic plane and $\mathrm{RD}$ for the crystallographic direction, as presented in (a) at the bottom of Figure 1. Three primary colors, blue (001), red (011), and green (111), for ND and $\mathrm{RD}$ were blended at 256 linear levels corresponding to the angle of deviation from each vertex.

To map the grain boundaries, the boundary between secondary and primary recrystallized grains was classified by computational processing according to three categories, in which the deviation angles of orientation of mutual grains were photographed to a width of 1 pixel to represent on the display a deviation angle of within $10^{\circ} ; 2$ pixels within $25^{\circ}$, and 3 pixels, of more than $25^{\circ}$. These boundary angles are shown in (b) at the bottom of Figure 1. A large boundary width shows a high deviation angle between mutual grains.

\section{EXPERIMENTAL RESULTS}

Figure 1 shows computer color maps of the orientation of secondary and primary recrystallized grains after secondary recrystallization annealing for (B) $3 \mathrm{~h}$, (C) $7 \mathrm{~h}$, (D) $27 \mathrm{~h}$, and (E) $50 \mathrm{~h}$ at $850^{\circ} \mathrm{C}$. The bottom of Figure 1 shows an explanation of a color display of (a) a stereographic projection showing the orientation of secondary and primary recrystallized grains, and (b) the deviation angle between the orientation of mutual grains.

From the color maps of (B) in Figure 1, it can be seen that a secondary recrystallized Goss grain of elliptical form, $80 \mu \mathrm{m}$ long in the rolling direction and $50 \mu \mathrm{m}$ in the 

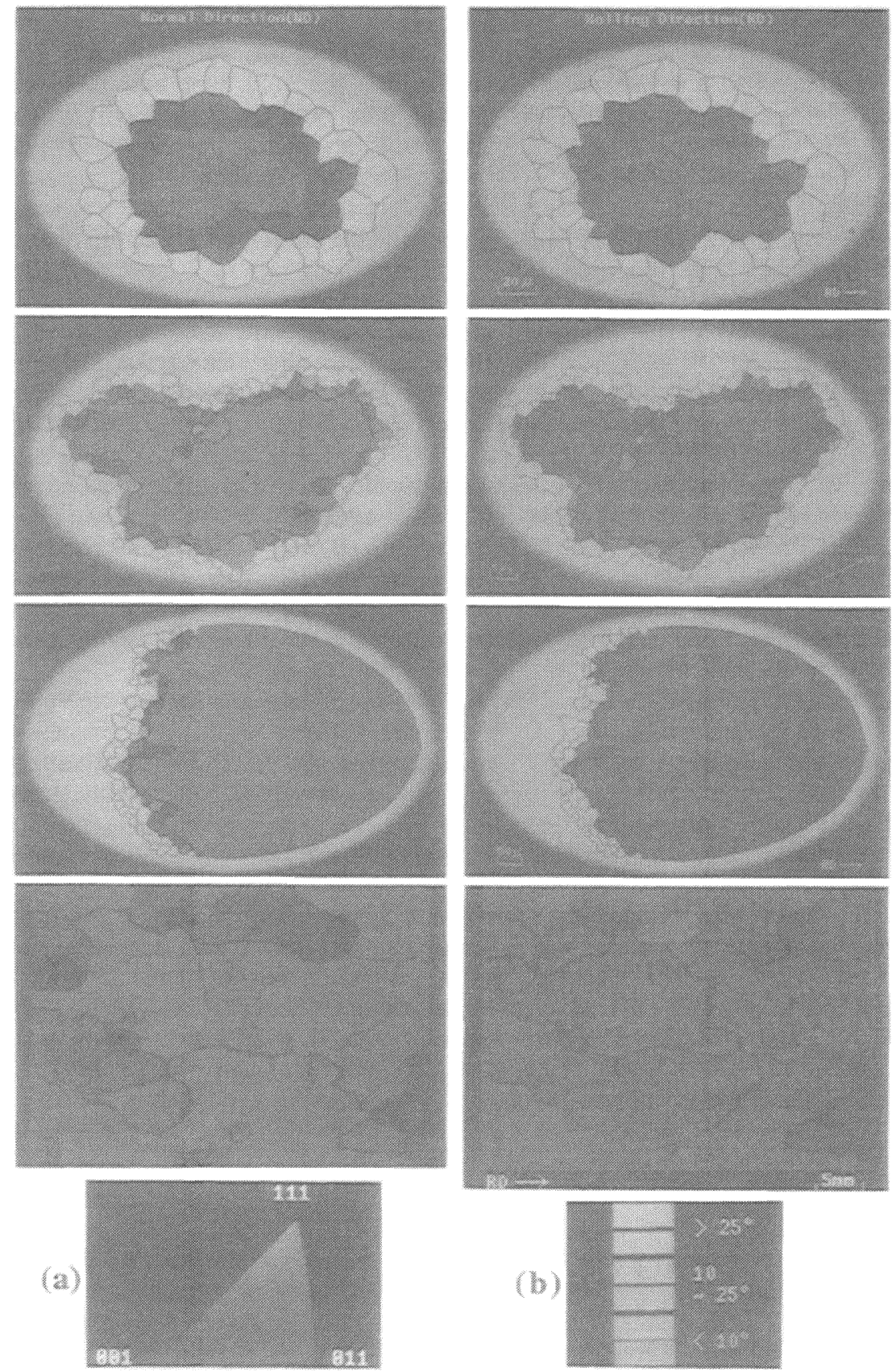

Figure 1 Computer color maps of the orientation of secondary and primary recrystallized grains parallel to the normal direction (ND) and rolling direction (RD) after secondary recrystallization annealing for $3 \mathrm{~h}, 7 \mathrm{~h}, 27 \mathrm{~h}$, and $50 \mathrm{~h}$ at $850^{\circ} \mathrm{C}$. Bottom shows color display of (a) stereographic projection of three basic colors, blue (001), red (011), and green (111), and (b) boundary width showing the deviation angle of orientation of mutual grains. 
transverse direction, grew preferentially at the $1 / 10$ depth beneath the surface of the silicon steel sheet. Most of the primary recrystallized grains surrounding this secondary recrystallized Goss grain are oriented to $\{$ hk0 $0<001>$ and $\{110\}<001>$, while very few are oriented to $\{100\}<001>,\{100\}<011>$, and $\{111\}<112>$. In particular, as can be seen very clearly in the ND color map of (B) in Figure 1, all the primary recrystallized grains around the periphery of the secondary recrystallized Goss grain have a blue or near-blue color, representing a highly oriented $<001\rangle$ axis.

In the color maps of (C) in Figure 1, four secondary recrystallized Goss grains $100-350 \mu \mathrm{m}$ in size grew preferentially in a state elongated in the rolling direction. The deviation angle for the orientation of these Goss grains is within 2 degrees. Around the periphery of the secondary recrystallized Goss grains, primary recrystallized grains of $\{\mathrm{hk} 0\}<001>$ and $\{111\}<112>$ were found in colonies of several primary recrystallized grains, while those of $\{110\}<001>,\{100\}<001>$, and $\{111\}<110>$ were in an isolated state.

In the color maps of (D) in Figure 1, a giant secondary recrystallized Goss grain can be seen. The boundary between the secondary recrystallized Goss grain and primary recrystallized grains exhibits a zigzag morphology due to a difference in the degree of consumption of primary recrystallized grains by the secondary recrystallized Goss grain. The primary recrystallized grains which resisted to consumption by secondary recrystallized Goss grains were found to be $\{100\}<100>\sim<0 \mathrm{k} 1>$.

In the color maps of $(E)$ in Figure 1, giant secondary recrystallized Goss grains with sizes of $3 \sim 12 \mathrm{~mm}$ can be seen, and there are no primary recrystallized grains due to secondary recrystallization annealing, which was conducted for a long time of $50 \mathrm{~h}$ at $850^{\circ} \mathrm{C}$. It should be noticed that the ND color map of the secondary recrystallized Goss grains is red with (110) crystallographic planes, and the RD color map is blue with a [001] axis. In particular, the secondary recrystallized Goss grains are highly aligned to the [100] axis rather than the (110) crystallographic plane. [See also, (a) schematic diagram of secondary recrystallized grains and (b) related (100) pole figure of Figure 2.]

Moreover, it should be noticed that the alignment in the (110)[001] orientation of secondary recrystallized Goss grains is better for large grains, and worse for smaller ones.

\section{DISCUSSION}

\section{Preferential growth of secondary recrystallized Goss grains during secondary recrystallization}

The sequence for nucleation and preferential growth of secondary recrystallized Goss grains during secondary recrystallization (Inokuti, 1988 and Inokuti et al., 1987) is shown in Figures 3 and 4, which are schematic diagrams of the steel sheet surface and crosssection, respectively, of a grain oriented silicon steel sheet.

(A) in Figure 3 and (a) in Figure 4 denote colonies of large primary recrystallized (110)[001] grains in defined zones at the $1 / 10$ depth beneath the steel surface prior to secondary recrystallization annealing. From a comparison of the grain size of the primary recrystallized grains at the near-surface and center of the silicon steel sheet after as-decarburized and primary recrystallized annealing in Table 1, it should be emphasized that the grain size of the large primary recrystallized grains with (110)[001] 

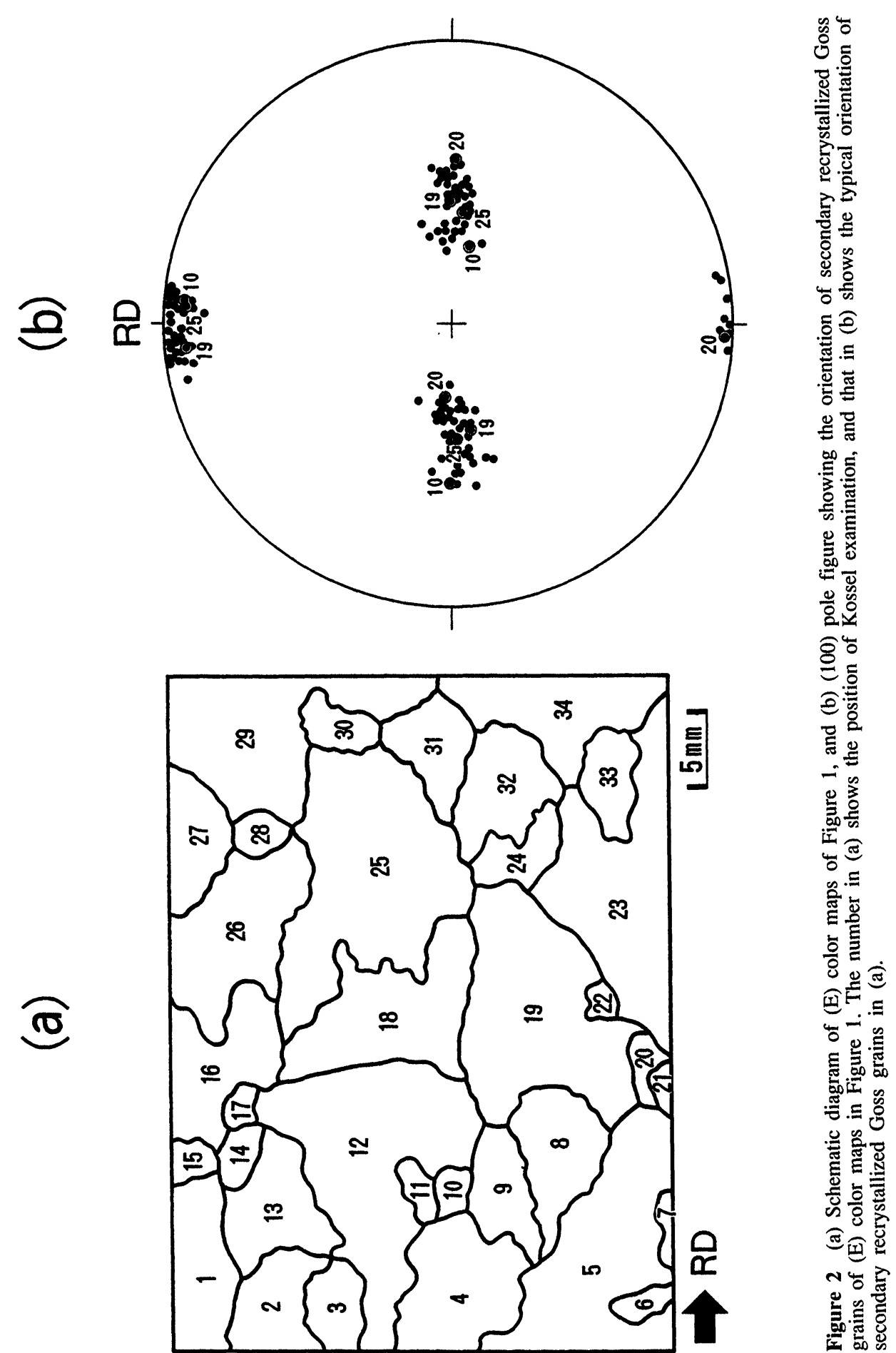
orientation at the near-surface of the silicon steel sheet is 2-6 times as large as that of the average matrix grains, and they form clearly in defined zones, which will be discussed in the next section.

(B) in Figure 3 and (b) in Figure 4 denote the preferential growth of secondary recrystallized Goss grains in the defined zones at the initial stage of the secondary recrystallization process. With subsequent secondary recrystallization annealing, the colonies of large primary recrystallized (110)[001] grains show preferential growth. A typical example can be seen in the (B) color map of Figure 1, in which the secondary recrystallized Goss grain with an elliptical morphology of $80 \mu \mathrm{m}$ in the rolling direction and $50 \mu \mathrm{m}$ in the transverse direction grew preferentially. In particular, it should be emphasized from the (B) color maps of Figure 1 that all the primary recrystallized grains around the periphery of the secondary recrystallized Goss grain had a blue or near-blue color representing $\{\mathrm{hk} 0\}<001>$ containing the Goss orientation (Inokuti et al., 1993).

(C) in Figure 3 and (c) in Figure 4 illustrate further secondary recrystallization annealing, in which several secondary recrystallized Goss grains grew in an agglomerated and coalesced state. A typical example of this can be seen in (C) color maps of Figure 1 , in which four secondary Goss grains which had coalesced to $100-350 \mu \mathrm{m}$ in size grew preferentially in a state elongated in the rolling direction. Moreover, it should be noted that the deviation angle for the orientation of these coalesced secondary Goss grains is small, being within 2 degrees (Inokuti et al., 1993).

It should be pointed out that the coalescence of the Goss grains in the initial stage of secondary recrystallization annealing is similar to the geometrical coalescence proposed by (Nielsen, 1966). This was later verified by (Sakai et al., 1980 and 1982), who used the etch-pit method and designated geometrical coalescence by the terminology of "pre-Goss" grains.

(D) in Figure 3 and (d) in Figure 4 illustrate further secondary recrystallization annealing, in which a secondary recrystallized Goss grain grows in area with a pancake morphology and grain size of 600-1000 $\mu \mathrm{m}$. A typical example can be seen in the (D) color maps of Figure 1, in which the boundary between the secondary recrystallized Goss grain and primary recrystallized grains exhibits a zigzag morphology due to a difference in the degree of consumption of primary recrystalized grains by the secondary Goss grain. In this case, it is evident that primary recrystallized grains with $\{100\}<001>$, $\{100\}<0 \mathrm{k} 1>$, and $\{100\}<011>$ orientations are resistant to consumption by secondary recrystallized Goss grains, and those with $\{110\}<001>$ and $\{111\}<112>$ orientations are easily consumed by secondary recrystallized Goss grains.

(E) in Figure 3 and (e) in Fig 4 illustrate final secondary recrysallization annealing, when the full thickness of the silicon steel sheet is occupied by giant secondary recrystallized Goss grains, which ultimately extended several millimeters in length along the sheet surface. A typical example can be seen in the (E) color maps of Figure 1,

Table 1 Grain size of the primary recrystallized grains at the near-surface and center of the silicon steel sheet after as-decarburized and primary recrystallization annealing, prior to secondary recrystallization treatment.

\begin{tabular}{|c|c|c|}
\hline & (110)[001] grains & Average matrix grains \\
\hline $1 / 10$ depth under surface & $33-98 \mu \mathrm{m}$ & $18 \mu \mathrm{m}$ \\
\hline Center & $13-25 \mu \mathrm{m}$ & $17 \mu \mathrm{m}$ \\
\hline
\end{tabular}




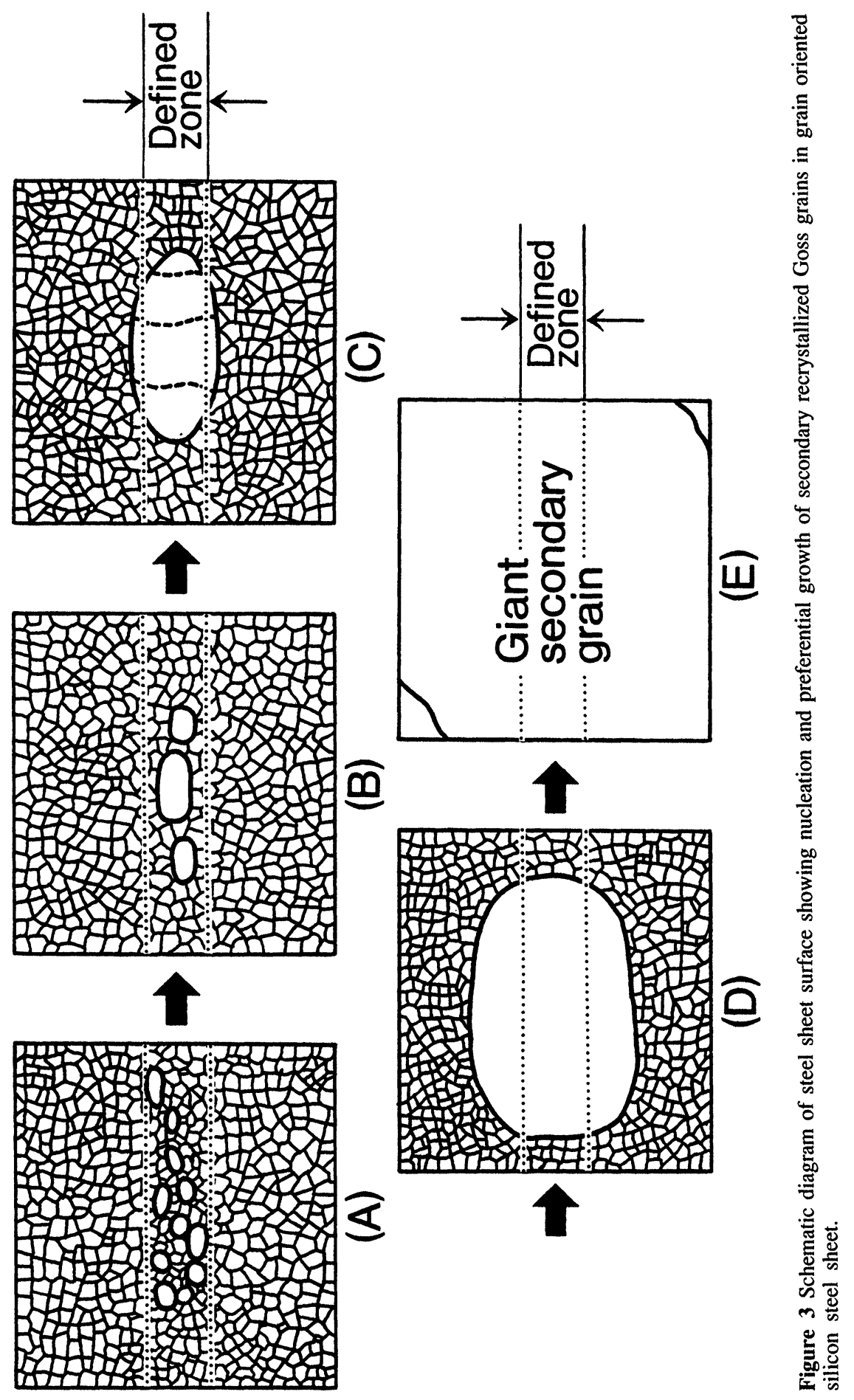



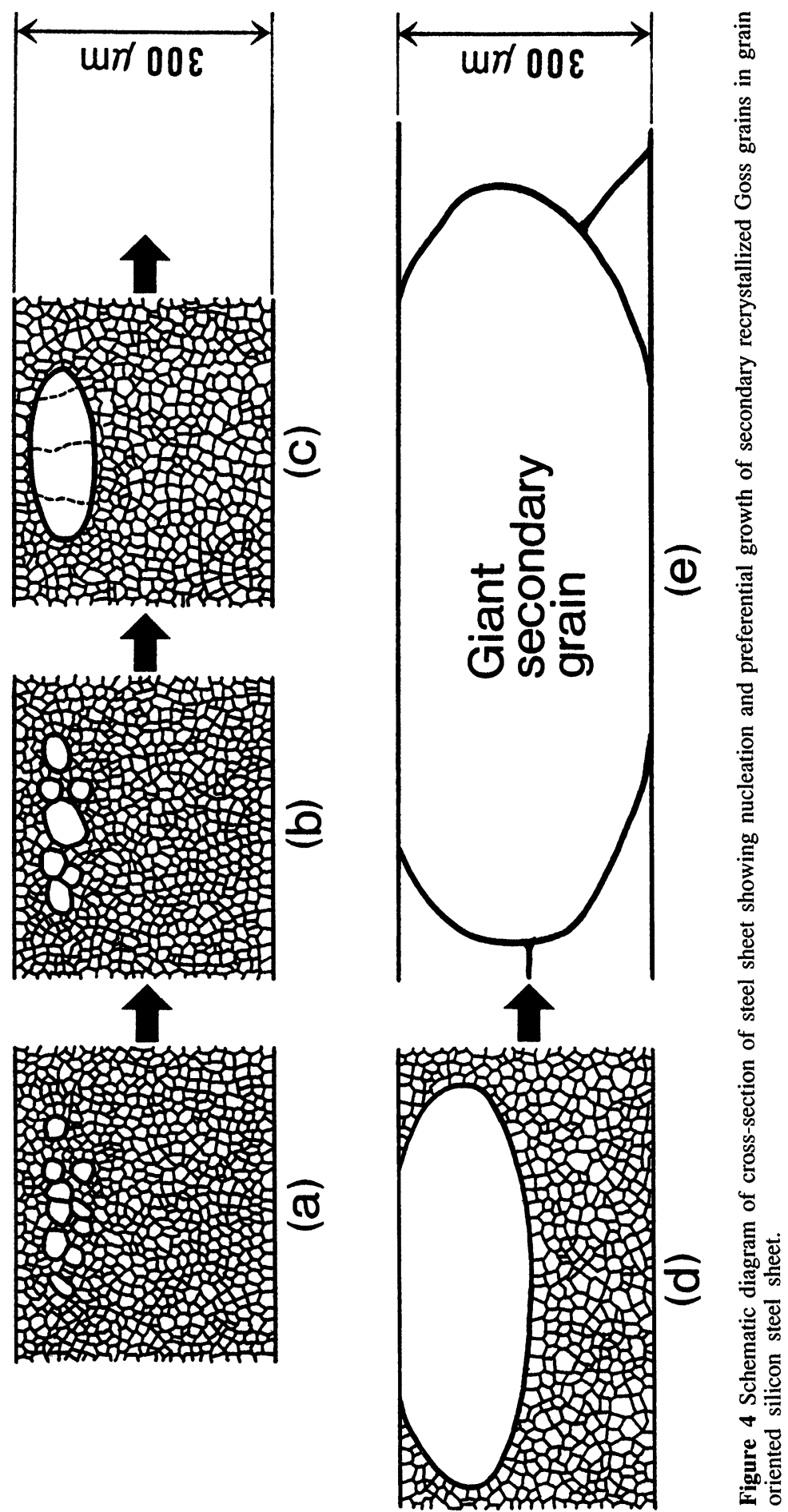
in which giant secondary recrystallized Goss grains with sizes of $3 \sim 12 \mathrm{~mm}$ can be seen. The ND color map of secondary recrysallized Goss grains is red with (110) crystallographic planes, while the RD color map is blue with a [001] axis. In this case, the orientation of secondary recrystallized Goss grains is highly aligned to the [100] axis rather than the (110) crystallographic plane, strongly supporting the importance of the existence of defined zones in silicon steel sheet after as-decarburized and primary recrystallized treatment.

\section{Role of defined zones in preferential formation of secondary recrystallized Goss grains}

The nuclei which preferentially develop secondary recrystallized Goss grains are generated from the highly oriented (110)[001] areas near the surface of hot-rolled silicon steel sheet (Inokuti, 1988, Gol' dshteyn et al., 1978 and Inokuti et al., 1986). As shown in the schematic diagram in Figure 5, elongated and recrystallized grains have been subjected to detailed TK examination and computer color mapping (Inokuti et al., 1994) at various thickness positions in the hot-rolled silicon steel sheet. At the 1/10 depth, the size of the elongated grains was heterogeneous, and the elongated grains with Goss orientation were extremely large. Highly oriented (110)[001] and strain-free areas $200 \sim 1000 \mu \mathrm{m}$ long and 100 200 $\mu \mathrm{m}$ wide, which are considered to be the origin of nuclei of secondary recrystallized Goss grains, have formed in the rolling direction inside the elongated matrix grains with the Goss orientation.

These highly oriented (110)[001] areas are inherited by the structure memory (Inokuti, 1988 and Inokuti et al., 1994) in the vicinity of the surface of the silicon steel sheet after as-decarburized and primary recrystallized annealing. Figure 6 shows the inheritance mechanism by the structure memory of secondary recrystallized Goss grains from the original hot-rolled steel to the as-decarburized and primary recrystallized steel sheet.

From color maps of Figure 1, the defined zone in which large primary recrystallized grains with the $\{110\}<001>$ orientation form is $100 \sim 200 \mu \mathrm{m}$ wide. The width of this defined zone in Figure 3 and 4 is consistent with that of the highly oriented (110)[001] areas in the elongated Goss matrix grains at the 1/10 depth beneath the surface of hotrolled silicon steel sheet. This fact supports the view that primary recrystallized grains with (110)[001] and $\{$ hk 0$\}<001>$ orientations in the defined zone form with high frequency, and those with $\{111\}<112>$ orientation rarely form.

\section{CONCLUSION}

Computer color maps of secondary and primary recrystallized grains which formed during secondary recrystallization annealing in grain oriented silicon steel were produced with an image analyzer using crystallographic orientation data from a Kossel examination.

(1) With secondary recrystallization annealing for $3 \mathrm{~h}$ at $850^{\circ} \mathrm{C}$, a secondary recrystallized Goss grain in the form of an ellipse of $80 \mu \mathrm{m}$ in the rolling direction and $50 \mu \mathrm{m}$ in the transverse direction grew preferentially at the $1 / 10$ depth beneath the surface of the silicon steel sheet.

(2) With secondary recrystallization annealing for $7 \mathrm{~h}$ at $850^{\circ} \mathrm{C}$, four secondary recrystallized Goss grains coalesced sizes of $100-350 \mu \mathrm{m}$, growing preferentially in an elongated shape in the rolling direction. 


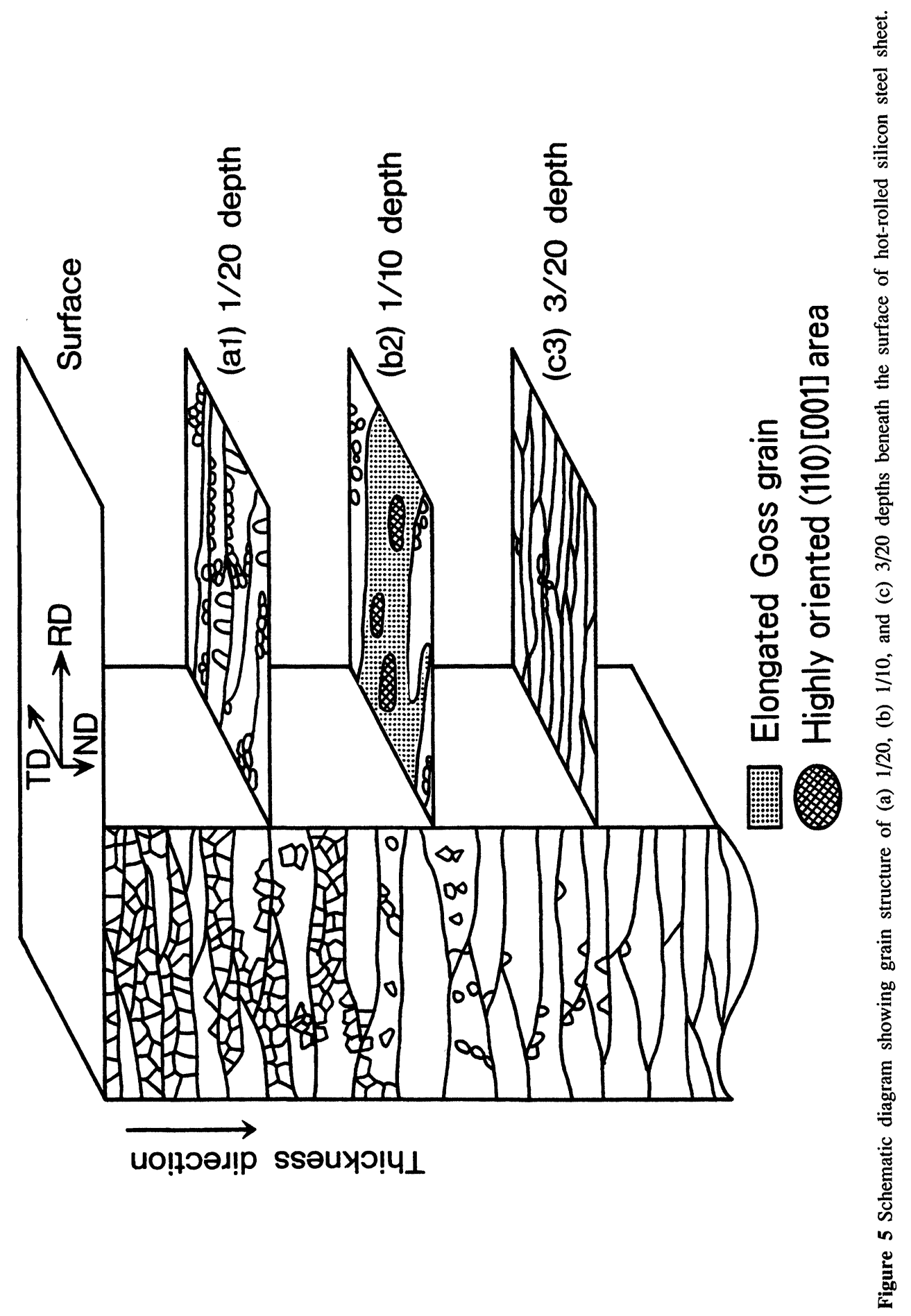




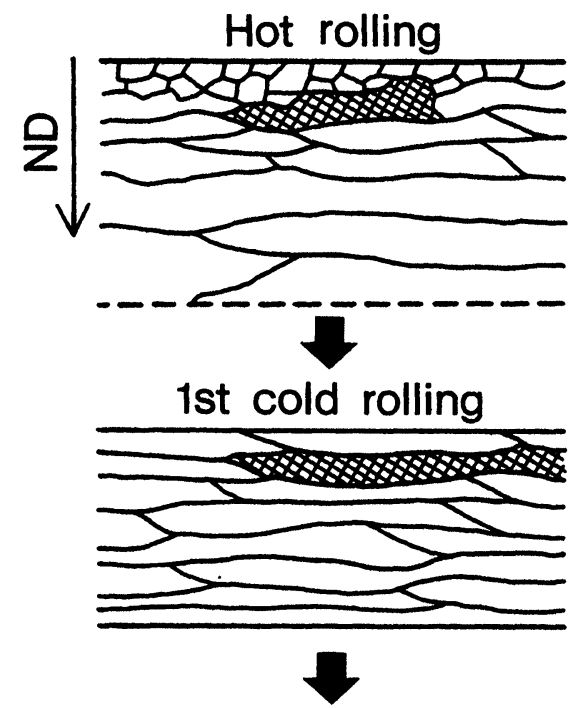

1 : Generation of Goss nuclei (Highly oriented (110) [001] area)

2 : Deformed structure with $\{111\}\langle 112\rangle$ orientation

Intermediate annealing

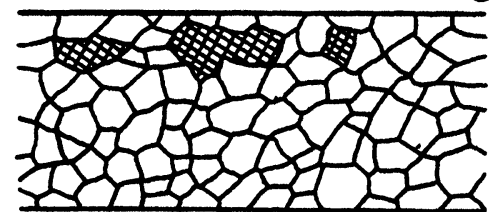

3 : Preferential formation of (110) [001] grain inside matrix band with $\{$ hk0 $\}\langle 001\rangle$ orientation

7

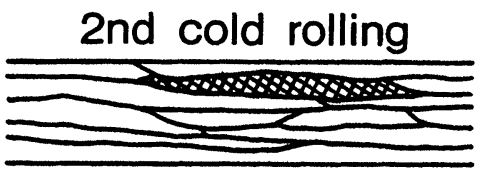

4 : Deformed structure $\{111\}\langle 112\rangle$ orientation

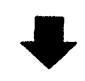

Decarburization and primary recrystallization annealing .

\section{5 : Colonies of large primary grains with (110) [001] orientation}

\section{Small areas of inheritance of Goss nuclei}

Figure 6 Schematic diagram of the inheritance mechanism by the structure memory for original hotrolled silicon steel sheet up to as-decarburized and primary recrystallized annealing. 
(3) With secondary recrystallization annealing for $27 \mathrm{~h}$ at $850^{\circ} \mathrm{C}$, a secondary recrystallized Goss grain exhibited a zigzag morphology due to a difference in the degree of consumption of primary recrystalized grains by the secondary recrystallized Goss grain.

(4) Primary recrystallized grains with $\{100\}<001>,\{100\}<0 \mathrm{k} 1>$, and $\{100\}<001>$ orientations were resistant to consumption by secondary recrystallized Goss grains, and those with orientations of $\{110\}<001>$ and $\{111\}<112>$ were easily consumed by secondary recrystallized Goss grains.

(5) After secondary recrystallization annealing for $50 \mathrm{~h}$ at $850^{\circ} \mathrm{C}$, the full thickness of the silicon steel sheet was occupied by giant secondary recrystallized Goss grains which ultimately extended to several millimeters in length along the sheet surface.

(6) The ND color map of giant secondary recrystallized Goss grains with sizes of 3 12 $\mathrm{mm}$ were red with (110) crystallographic planes, and the RD color map was blue with a [001] axis.

(7) The orientation of the secondary recrystallized Goss grains was highly aligned to the [001] axis rather than the (110) crystallographic plane.

(8) It is considered that the preferential growth of secondary recrystallized Goss grains took place in a defined zone at the 1/10 depth beneath the surface of as-decarburized and primary recrystallized steel sheet, this zone being inherited by the structure memory from the $1 / 10$ depth beneath the surface of hot-rolled silicon steel sheet.

\section{References}

Furukimi, O., Yamamoto, A., Imanaka, A. and Nishiike, U. (1984). Automation of Orientation Analysis Using Kikuchi Patterns Obtained from Very Small Regions. Tetsu-to-Hagane, 70, S565.

Gol' dshteyn, V. YA., Pashchenko, S. V. and Petrova, T. A. (1978). Influence of the Initial State of Alloy $\mathrm{Fe}-3 \% \mathrm{Si}$ on the Processes of Structure and Texture Formation during Alternating Cycles of Deformation and Recrystallization. Phys. Met. Metall., 46, No. 1, 109-112.

Harase, J. and Shimizu, R. (1986). The Study on the Grain Growth Behaviour of 3\%Si-Fe by SEMECC-ECP, Bull. Japan Inst. Metals, 25, 1009-1017.

Inokuti, Y. Shimizu, Y. and Shimanaka, H. (1980). Crystallographic Orientation Determination of Small Areas in Grain Oriented Silicon Steel by Transmission Kossel Technique. Kawasaki Steel Technical Report, 12, 297-306.

Inokuti, Y., Maeda, C., Ito Y. and Shimanaka H. (1982). Analysis of Crystallographic Orientation at an Incipient Stage of Secondary Recrystallization of Grain Oriented Silicon Steel by Transmission Kossel Technique. Sixth International Conference on Textures of Materials (II), ISIJ, Tokyo, (1982), 948-957.

Inokuti, Y., Maeda, C., Ito., Y. and Shimanaka, H. (1983). Transmission Kossel Study of Origin of Goss Texture in Grain Oriented Silicon Steel. Trans. ISIJ, 23, 440-449.

Inokuti, Y., Maeda. C. and Ito, Y. (1985). Transmission Kossel Study of Goss Grains in Grain Oriented Silicon Steel Containing a Small Amount of Molybdenum. Trans. ISIJ, 25, 233-241.

Inokuti, Y., Maeda, C. and Ito, Y. (1986). Observation of Generation of Secondary Nuclei in a Grain Oriented Silicon Steel Dheets Illustrated by Computer Color Mapping. J. Japan Inst. Metals, 50, 874-878.

Inokuti, Y., Maeda, C. and Ito, Y. (1987). Computer Color Mapping of Configuration of Goss Grains after an Intermediate Annealing in Grain Oriented Silicon Steel. Trans. ISIJ, 27, 139-144.

Inokuti, Y. (1988). Development of Grain Oriented Silicon Steel Containing a Small Amount of Molybdenum and Mechanism of Secondary Recrystallization with Goss Orientation. J. Japan Inst. Metals, 27, 250-257.

Inokuti, Y., Yanagisawa, M. and Gotoh, C. (1990). Structure of <110> Fiber Texture in the Central Area of Hot Rolled Silicon Steel Sheet, J. Japan Inst. Metals, 54, 1183-1190. 
Inokuti, Y. and Saito, F. (1991). Configuration of Primary Grains Resistant to Comsumption by Secondary Goss Grains. J. Japan Inst. Metals, 55, 1167-1173.

Inokuti, Y., Gotoh, C., Yanagisawa, M. and Saito, F. (1993). Preferential Growth of Goss Grains at Incipient Stage of Secondary Recrystallization in Grain Oriented Silicon Steel Sheet. J. Japan Inst. Metals, 57, 621-627.

Inokuti, Y. and Saito, F. (1994). Structural Variation along Thickness Direction near Surface of Hotrolled Silicon Steel Sheet. J. Japan Inst. Metals, 58, 605-612.

Maeda, C., Inokuti, Y. and Ito., Y. (1986). Orientation Analyses of Individual Grains in a Grain Oriented Silicon Steel Sheets by means of Kossel Diffraction Patterns and Its Illustration by Computer Color Mapping. J. Japan Inst. Metals, 50, 869-873.

Miyajima, A., Furukimi, O., Yanagisawa, M. and Saito, F. (1990). Image Processing Technology or Material Evaluation. Kawasaki Steel Technical Report, 22, 72-78.

Nielsen, J., P. (1966). "Recrystallization, Growth and Textures". [ASM, Metal Park, Ohio] p.141.

Sakai, T., Shiozaki, M. and Koukai, K. (1980). Microscopic Observation of Secondary Recrystallization in High Permeability Grain-oriented Silicon Steel. Tetsu-to-Hagane, 66, S428.

Sakai, T., Matsuo, M., Tanino, M., Shindo, T. and Shiozaki M. (1982). Secondary Recrystallization Process of High Permeability Grain Oriented Silicon Steel. Sixth International Conference on Textures of Materials, (II), 1982, [ISIJ, Tokyo] p. 938-947. 